\title{
DNA methylation and genetic degeneration of the $Y$ chromosome in the dioecious plant Silene latifolia
}

\author{
José Luis Rodríguez Lorenzo * (iD, Roman Hobza and Boris Vyskot
}

\begin{abstract}
Background: S. latifolia is a model organism for the study of sex chromosome evolution in plants. Its sex chromosomes include large regions in which recombination became gradually suppressed. The regions tend to expand over time resulting in the formation of evolutionary strata. Non-recombination and later accumulation of repetitive sequences is a putative cause of the size increase in the $Y$ chromosome. Gene decay and accumulation of repetitive DNA are identified as key evolutionary events. Transposons in the $X$ and $Y$ chromosomes are distributed differently and there is a regulation of transposon insertion by DNA methylation of the target sequences, this points to an important role of DNA methylation during sex chromosome evolution in Silene latifolia. The aim of this study was to elucidate whether the reduced expression of the $\mathrm{Y}$ allele in S. latifolia is caused by genetic degeneration or if the cause is methylation triggered by transposons and repetitive sequences.

Results: Gene expression analysis in S. latifolia males has shown expression bias in both $X$ and $Y$ alleles. To determine whether these differences are caused by genetic degeneration or methylation spread by transposons and repetitive sequences, we selected several sex-linked genes with varying degrees of degeneration and from different evolutionary strata. Immunoprecipitation of methylated DNA (MeDIP) from promoter, exon and intron regions was used and validated through bisulfite sequencing. We found DNA methylation in males, and only in the promoter of genes of stratum I (older). The $Y$ alleles in genes of stratum I were methylation enriched compared to $X$ alleles. There was also abundant and high percentage methylation in the $\mathrm{CHH}$ context in most sequences, indicating de novo methylation through the RdDM pathway.

Conclusions: We speculate that TE accumulation and not gene decay is the cause of DNA methylation in the S. latifolia Y sex chromosome with influence on the process of heterochromatinization.
\end{abstract}

Keywords: Epigenetics, Sex chromosomes, Silene latifolia, Y degeneration, Sex-linked genes, DNA methylation, Sodium bisulfite, Immunoprecipitation

\section{Background}

While sex chromosomes in mammals are ancient, those in dioecious plants are evolutionarily young. The plant $\mathrm{Y}$ chromosome, which is largely non-recombining, represents a unique part of the genome. In contrast to the small mammalian Y chromosome, heteromorphic Y chromosomes in angiosperms are often the largest chromosomes in the male genome, e.g., in Silene latifolia and Cannabis sativa [1]. S. latifolia, a dioecious plant of the Caryophyllaceae family

\footnotetext{
* Correspondence: rodriguez@ibp.cz

Plant Developmental Genetics, Institute of Biophysics v.v.i, Academy of Sciences of the Czech Republic, Královopolská 135, 61265 Brno, Czech Republic
}

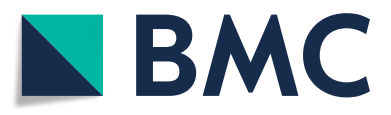

(c) The Author(s). 2018 Open Access This article is distributed under the terms of the Creative Commons Attribution 4.0 International License (http://creativecommons.org/licenses/by/4.0/), which permits unrestricted use, distribution, and reproduction in any medium, provided you give appropriate credit to the original author(s) and the source, provide a link to the Creative Commons license, and indicate if changes were made. The Creative Commons Public Domain Dedication waiver (http://creativecommons.org/publicdomain/zero/1.0/) applies to the data made available in this article, unless otherwise stated.

with sex chromosomes, originated around 10 million years ago. It is a model organism for studying sex chromosome evolution in plants. A distinguishing feature shared by independently evolved sex chromosomes is the presence of a suppressed recombination region on a sex-specific chromosome in the heterogametic sex. The $\mathrm{X}$ chromosome in S. latifolia is submetacentric and two arms, $\mathrm{p}$ and $\mathrm{q}$, can be identified. On the other hand, the Y chromosome is metacentric and it is about 1.4 times larger than the $\mathrm{X}$ chromosome. The pseudoautosomal region (PAR) is located in the short subtelomeric region of the $\mathrm{p}$ arm on the $\mathrm{X}$ chromosome and the $\mathrm{q}$ arm of the Y chromosome. The non-recombining region includes at least two 
sex-determining loci; a gynoecium suppression function (GSF) and a stamen promoting function (SPF) [2, 3]. It has been suggested that $S$. latifolia Y chromosome gradually stopped recombining [4]. Sex chromosome pairs include regions in which recombination became suppressed at different times. These non-recombining regions tend to expand over evolutionary time resulting in the of evolutionary strata formation. The S. latifolia X Y sex chromosome pair has at least two strata, with the more recent stratum adjacent to the recombining pseudo-autosomal region (PAR) [3]. According to Kazama and Zluvova [5, 6], there is a large pericentric inversion between $X$ and $Y$ chromosomes. By comparing the Y-linked genes analysed in the presented study with the corresponding X-linked copies (Fig. 1), gene arrangement differences are evident. Cessation of recombination between large parts of the sex chromosomes is the most probable cause of increase in the size of the $\mathrm{Y}$ chromosome. Two important processes are involved in non-recombining regions of a genome. The first is accumulation of various types of repetitive DNA sequences such as transposable elements and tandem repeats. The other is gene degeneration [7]. The accumulation of many types of DNA sequence repeats (satellites, microsatellites, plastid sequences, transposons) may play an indirect (epigenetic) role in

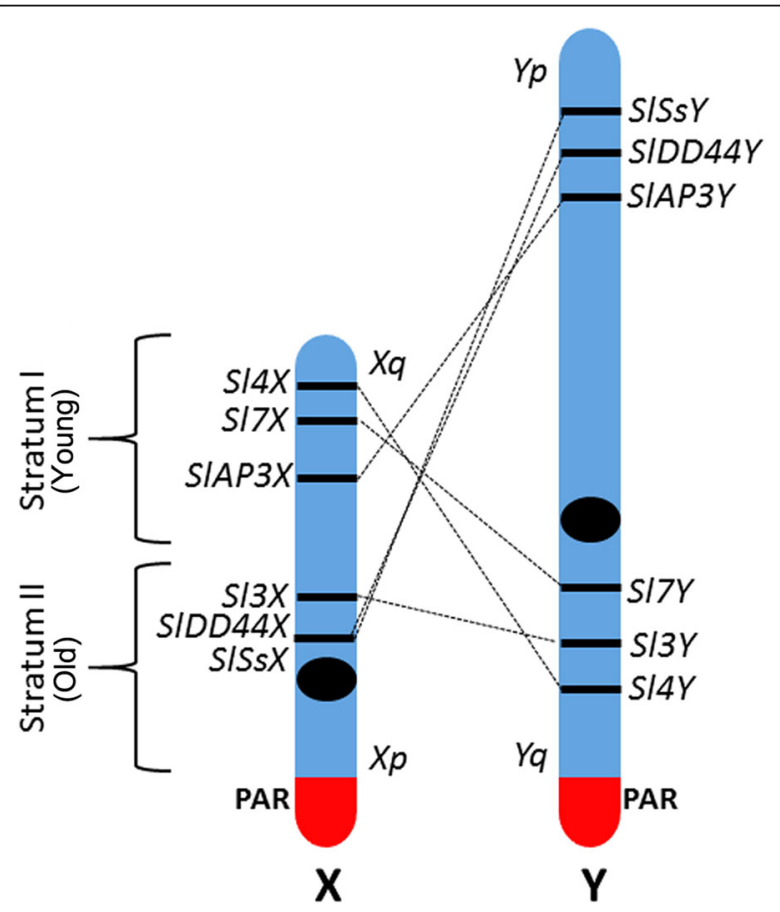

Fig. 1 Schematic map (not in scale) of the six $X$ and $Y$ linked alleles under analysis in this study according to Hobza, Kazama and Zluvova $[2,5,6]$. The different gene rearrangement between both chromosomes was caused by regions that underwent chromosomal inversions. Strata distribution in the $\mathrm{X}$ chromosome according to Papadopulos [26]
Y-chromosome decay. Transposons are differently distributed in the $\mathrm{X}$ and $\mathrm{Y}$ chromosomes of S. latifolia [8]. Kubat [9] showed that the Ogre retrotransposon family evolved before the appearance of sex chromosomes but was mobilised after formation of the $\mathrm{Y}$ chromosome. These authors suggest that transposons could play a role in sex chromosome evolution in S. latifolia through epigenetic silencing mechanisms. Transposon insertion is frequently regulated by the genome itself (e.g. using RNAi machinery), resulting in DNA methylation of target sequences. Methylation spreads to regions surrounding transposons with local effect on the expression of linked genes [10,11].

In animals, DNA methylation plays an important part in the early stages of sex chromosome evolution and, degeneration of the $\mathrm{Y}$ chromosome is linked to epigenetic regulation [12]. Waddinton [13] defined epigenetics as "the branch of biology that studies the causal interactions between genes and their products which bring the phenotype into being", and can be understood as a system for selectively regulating genome information through activating or inactivating gene expression. DNA methylation can be divided into three types according to the sequence context of the cytosines, namely CG, CHG, and $\mathrm{CHH}(\mathrm{H}=\mathrm{A}, \mathrm{C}$, or $\mathrm{T})$. CG and CHG contexts are symmetrical unlike $\mathrm{CHH}$ context which is asymmetrical. The symmetrical nature of $\mathrm{CpG}$ context is critical to the maintenance mechanism which is performed by conserved Dnmt1 DNA methyltransferases. The mechanisms of methylation in the mCHG and $\mathrm{mCHH}$ contexts are unique to plants [14]. The Methylation levels in each context differ between plant species, with mCG varying $\sim 3 \times$, mCHG $\sim 9 \times$, and $\mathrm{mCHH} \sim 16 \times[15]$. The effect of methylation on gene expression is highly dependent upon the type of methylation as well as the pattern of that methylation within or outside the gene [16]. In plants, de novo methylation takes place in a $\mathrm{CHH}$ context and is established by transcription of the two RNA polymerases: POLYMERASE IV (Pol IV) and Pol $V$. The Pol $I V$ and Pol $V$ transcripts serve as a template for the RNA-dependent RNA polymerase, generating double-stranded RNA which is digested by DICER-LIKE 3 activity into 24-nt sRNAs. The 24-nt sRNAs, signal DRM2 to initiate CHH methylation including an Argonaute complex. This mechanism has been described as RNA-directed DNA methylation (RdDM) [17]. The Y chromosome evolution in Carica papaya is linked to DNA methylation and heterochromatinisation [18]. This is the mechanism proposed to induce dioecy and the evolution of sex chromosomes, with suppression of meiotic recombination [19]. In S. latifolia, DNA methylation is also proposed as the mechanism underlying female sex suppression in the $\mathrm{Y}$ chromosome of male individuals [20].

This study is based on the general hypothesis that there is an epigenetic influence on sex determination 
and evolution of plant sex chromosomes. It is known that most of the alleles in the $\mathrm{Y}$ chromosome with existing X linked counterparts characterized in S. latifolia so far, have a partial Y expression insufficiency. The lack of recombination in the sex specific region leads to an accumulation of deleterious mutations and degeneration. The reduced effective population size of the Y chromosome is one of the main forces leading to degeneration [7]. Not only gene degradation, but DNA rearrangements and insertions of repetitive sequences and transposons can also affect the transcription of genes in the $\mathrm{Y}$ chromosome $[2,21,22]$. The aim of this study was to elucidate whether the reduced expression of the $\mathrm{Y}$ alleles is caused by genetic degeneration, or if the cause is methylation spread by transposons and repetitive sequences.

\section{Results}

\section{Expression results}

Expression of the genes SlAP3/SvAP3; SlDD44/SvDD44; $S l 3 / S v 3$; Sl4/Sv4; Sl7/Sv7; SlSs/SvSs was measured in tissues at different developmental stages: leaves in vegetative growth, leaves during the flowering stage and flower buds. The flower buds were selected from stage 7 to 10 according to Farbos [23]. These genes belong to stratum I (older) or stratum II (younger) of the $\mathrm{X}$ chromosome from the evolutionary point of view (Fig. 1). Full expression results can be found in Additional file 1.

Comparison of the expression for S. latifolia and $S$. vulgaris, the correlation plot shows a high correlation between S. latifolia male and S. vulgaris $\left(R^{2}=0.705\right)$ and between $S$. latifolia female and $S$. vulgaris $\left(\mathrm{R}^{2}=0.738\right)$. Expression data for the the vegetative stage revealed statistically significant differences between $S$. latifolia (male and female) and S. vulgaris on genes Sl3 and Sl7. The differences between $S$. latifolia male and female were found only in SIDD44. In S. latifolia males, the expression was biased on both alleles, $\mathrm{X}$ and $\mathrm{Y}$ (Fig. 2). The expression was biased towards the $\mathrm{X}$ allele in $\mathrm{Sl7}$, SIDD44, Sl3 and SlSs. On the other hand the expression was biased towards the Y allele in Sl4 and SIAP3.

\section{Sequence similarity and location}

The degree of similarity of promoter and intron regions in S. vulgaris, the X allele of S. latifolia and Y allele of S. latifolia, was calculated for each gene by neighbour-joining tree nucleotide alignment (Additional file 2). The greatest similarity between $\mathrm{X}$ and $\mathrm{Y}$ alleles was found in the SIDD44 intron region (91.13\%) and the smallest in the $S l 7$ promoter region $(42.8 \%)$. For the rest of the sequences, the similarity ranged from 50 to $70 \%$.

Regarding the location of the different genes, for the analysis, we used the sequence from the clones BAC30L22 and BAC241112 [24, 25]. The genes Sl7 and SlAP3 (stratum I), are included in these clones and we found that in their proximity $( \pm 1 \mathrm{~Kb})$ there are TEs and repetitive sequences, but no other genes were found close to Sl7 and SlAP3.

\section{Methylation in vegetative leaves DNA immunoprecipitation and bisulfite sequencing}

DNA methylation was analysed through MeDIP for three different regions of the genes described in the expression section. These were promoters, first exons and first introns (Fig. 2). The main differences were found in promoter regions. In $S$. vulgaris, methylation enriched promoters were found in SvAP3,Sv7, Sv3 and SvSs. However, in $S$. latifolia male plants, there was only enrichment in genes from stratum I (SlAP3, Sl4 and Sl7) and no enrichment in genes belonging to the stratum II. Regarding the $\mathrm{X}$ and $\mathrm{Y}$ alleles in S. latifolia males, the methylation enrichment on the stratum I genes, was only in the Y allele. Strikingly, only two genes were enriched in their intron region in S. vulgaris $S v 7$ and in S. latifolia female plants SIAP3.

To support the results from MeDIP, Bisulfite sequencing was used on those sequences with significant enrichment. The results (Fig. 3; Additional file 3) showed no common pattern of methylation among genes belonging to the same stratum or in the same kind of region (promoter, exon or intron) in these genes. A close- up on individual genes, showed a similar percentage of methylation in most of the sequences analysed. From the three different methylation contexts in plants $\mathrm{CG}, \mathrm{CHG}$ and $\mathrm{CHH}$, the $\mathrm{CHH}$ context was the most abundant in all situations except for the sequences from gen Sl7; Sl7YP, Sv7E and Sl7XE (Fig. 4; Additional file 3). There was on average, over $50 \%$ methylation for this context in most sequences.

\section{Discussion}

Most plant sex chromosomes appear to be of younger evolutionary origin than animal sex chromosomes and are, therefore, less degenerated [7, 26]. Degeneration of the genes analysed in this work, amongst others, has been analysed before by Marais [4] and Filatov [27]. Using whole genome analysis, rapid $\mathrm{Y}$ degeneration compared to the $\mathrm{X}$ allele has been reported by Papadopulos [26]. However, the latter found no significant differences in gene degeneration between evolutionary strata I and II. We need to bear in mind that these analyses were done on the coding sequence. In this study, we also performed a neighbour-joining tree nucleotide alignment test on promoter and intron regions. Even though we predicted that using the most divergent regions of the genes, there would be differences between strata I and II genes, no differences were found (Additional file 2). The similarity ranged from 50 to $70 \%$ in most cases. Given that variations in these sequences could affect methylation and therefore 


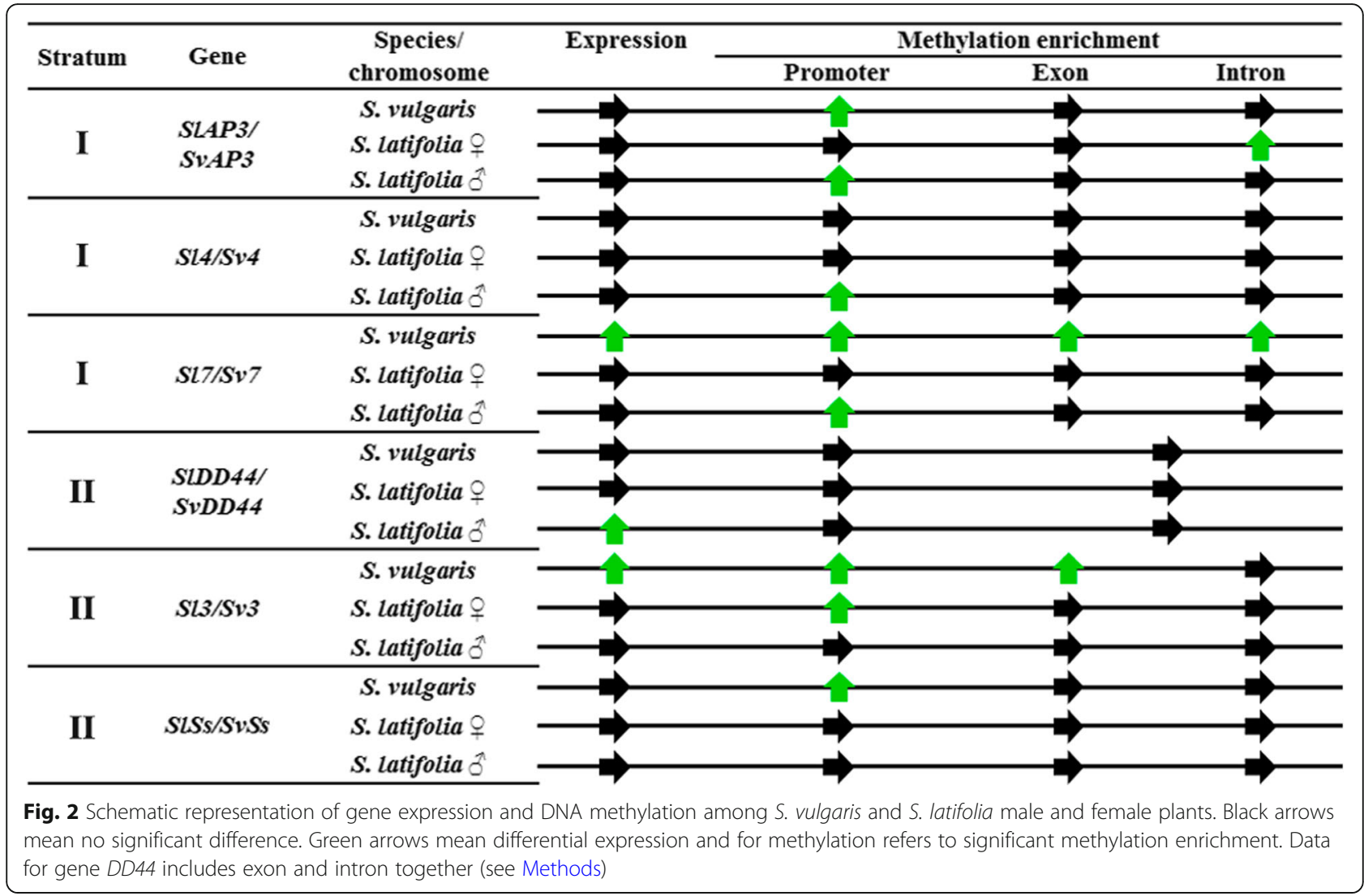

expression, the differences in methylation in the promoters of $\mathrm{X}$ and $\mathrm{Y}$ alleles may be influenced by modifications in the sequence per se. These modifications and not only sequences such as transposable elements and repetitive elements in the surroundings, may have a role in the differential methylation of both alleles [10, 19, 28].

Importantly, from the results of the MeDIP, only the promoters of genes from stratum I were differently methylated for male and female plants, suggesting a gene regulation difference between the strata. Either way, the methylation patterning males and females and also between $\mathrm{X}$ and $\mathrm{Y}$ alleles agree with the results in animals and some recent results in plants $[18,29]$. The modification of DNA using sodium bisulfite which we used for methylation contexts, is the most widespread technique for analysing site-specific cytosine methylation [30]. Non

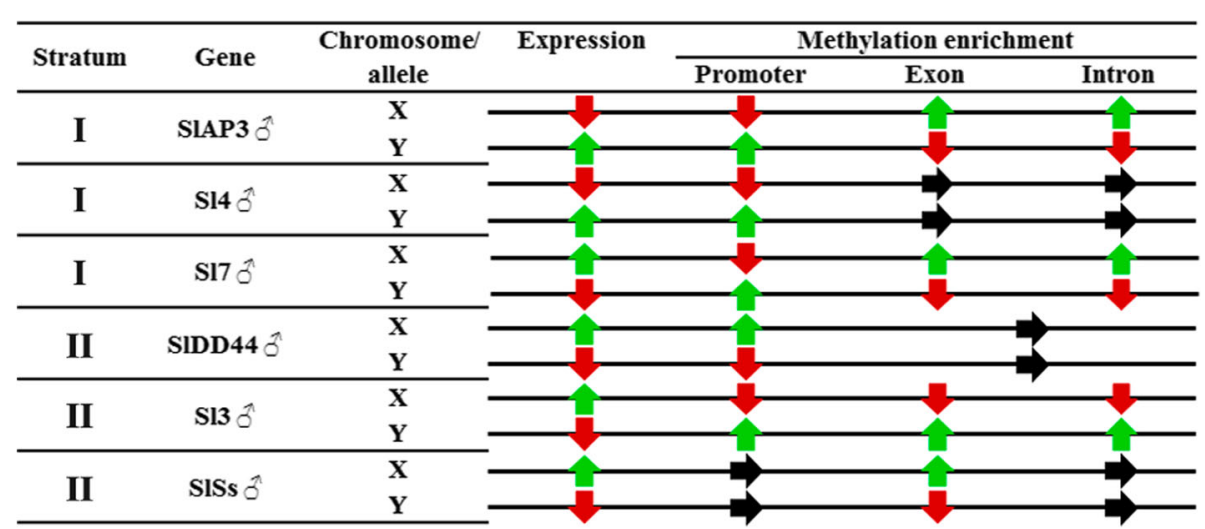

Fig. 3 Schematic representation of gene expression and DNA methylation forn $X$ and $Y$ alleles in male plants. Black arrows - no significant difference. Green arrows- differential overexpression and for methylation refers to significant methylation enrichment. Red arrows mean differential underexpression and for methylation refers to non-significant methylation enrichment Data for gene DD44 includes exon and intron together (see Methods) 


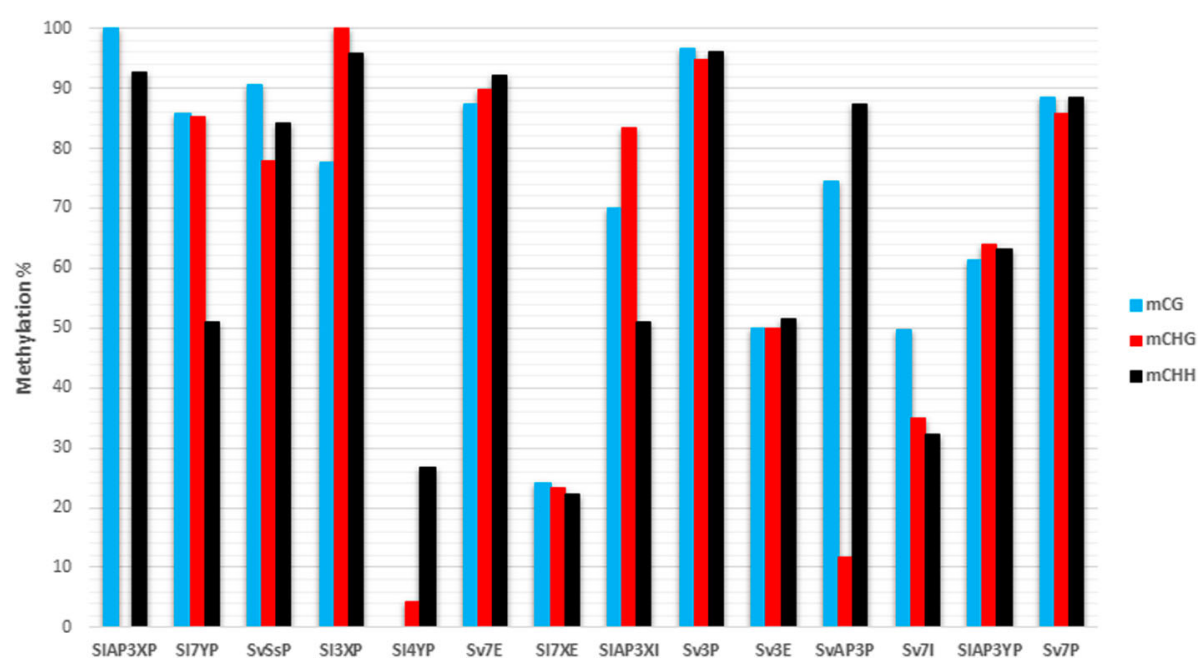

Fig. 4 Relative \% of CG, CHG and CHH methylation contexts in the different gene regions showing significant enrichment in the immunoprecipitation analysis. Gene name code: $X ; X$ allele, $Y$; $Y$ allele, $P$; promoter, E; exon, I; intron

CG context abundance and methylation are linked to repetitive and transposable elements [31]. Gehring [31] also indicated that a combination of CG and non CG contexts are related to gene silencing, though there are many exceptions. In most of the sequences analysed, the $\mathrm{CHH}$ methylation context is similar to $\mathrm{CG}$ and $\mathrm{CHG}$ contexts unlike other plants, which have a low methylation percentage in the $\mathrm{CHH}$ context $[32,33]$. The $\mathrm{CHH}$ methylation context is, however, increased in TEs and repetitive sequences and their location are important for methylation spread [11, 32, 34]. Li [35] and Gent [36] have reported that TEs within $1 \mathrm{~kb}$ of genes have higher levels of $\mathrm{CHH}$ methylation and are enriched in $24 \mathrm{nt}$ siRNA compared to genome wide averages. This suggests a regulation by RdDM. However, TEs that are in gene poor regions have a lower abundance of $24 \mathrm{nt}$ siRNA and reduced $\mathrm{CHH}$ methylation levels suggesting that they are regulated by different mechanisms. The relation of $\mathrm{RdDM}$ to $\mathrm{CHH}$ methylation appears to be enriched when transposon insertion occurs near or within a gene to maintain the repression of the inserted TE. The specific influence of TEs on the expression of neighboring genes appears to vary with the type of transposable element and is also related to chromatin context [37]. De novo methylation, flanking intergenic chromatin $1 \mathrm{~kb}$ up and downstream of transcription start sites and transcription end sites correspondingly has been suggested and these regions have been labelled $\mathrm{mCHH}$ islands [38]. It has been suggested that these islands indicate the transition between heterochromatin-associated TEs and euchromatin-associated genes. In Arabidopsis $\mathrm{CHH}$ is correlated to $\mathrm{CG}$ and $\mathrm{CHG}$ methylation contexts. As a general trend $\mathrm{CHH}$ methylation was present several nucleotides downstream of methylated CG contexts, and four nucleotides downstream CHG contexts. Therefore, repeats rich in CG and CHG methylation might induce increased levels of $\mathrm{CHH}$ methylation in the described sequence context [39].

In spite of the large number of non CG contexts present in our sequences, a whole $\mathrm{Y}$ chromosome methylation analysis will be needed to determine if methylation, non CG context and the presence of repetitive elements are connected. Moreover the high percentage of methylation in $\mathrm{Y}$ promoters does not involve silencing in all genes. In maize, the loss of methylation in $\mathrm{mCHH}$ islands found in expressed genes that are located near TEs does not impact gene expression, suggesting that promoter methylation at $\mathrm{CHH}$ islands in maize may not simply control gene expression but may also regulate nearby cis elements [38].

\section{Conclusions}

In summary, DNA methylation in genes under analysis in males was only found in the promoter of genes belonging to stratum I (older), of these genes, the $\mathrm{Y}$ alleles were more methylated than $\mathrm{X}$ alleles. There was high abundance and \% methylation in the $\mathrm{CHH}$ context in most sequences. These two main conclusions suggest that the age of the stratum in the chromosome affects methylation of the genes in the stratum. The position in the chromosome also has an influence on methylation as well as the proximity of TEs and repetitive sequences. We speculate that TE accumulation and not gene degeneration is the cause of high DNA methylation in S. latifolia Y sex chromosomes with influence on the heterochromatinisation of the chromosome. 


\section{Methods}

\section{Plant material}

All species of the genus Silene used in this study came from the collection of the Institute of Biophysics in Brno, Czech Republic. An inbred population (U15; 15 generations of brother $\mathrm{x}$ sister cross) of male and female S. latifolia was used in this research. Silene vulgaris, a close non-dioecious relative without sex chromosomes, was used as an out-group. Plant material was grown in a cultivation room under standard conditions (t $24 \mathrm{uC}$, 16 h light/8 h dark).

\section{Whole gene sequence characterization}

Full-length gene characterization was performed using the information available on the databases from the bacterial artificial chromosome (BAC) library characterized by Blavet [40]. We also used the information provided by the NGS data from $[26,41]$. Sequence management was done using Geneious v7.1 (Biomatters, http://www.geneious.com). The remaining unknown sequences of the $\mathrm{X}$ and Y alleles or $S$. vulgaris copies were identified by SMARTer ${ }^{\text {Ts }}$ RACE CDNA Amplification Kit (coding sequence) and by GenomeWalker $^{\mathrm{TM}}$ Universal Kit (promoter and intron sequence) both from Clontech (Mountain View, CA, USA). All the primers used in the characterization of the different sequences are listed in Additional file 4: Table S1. Total DNA and RNA were isolated from leaves and they were used as a template for the amplification reactions. Genomic DNA was isolated from young leaves using DNAeasy Plant Mini Kit (Qiagen, Dusseldorf, Germany). RNA was isolated from $75 \mathrm{mg}$ of frozen tissue according to RNeasy Plant Mini Kit (Qiagen, Dusseldorf, Germany). RNA integrity was tested in agarose gel under denaturing conditions. Removal of primers and nucleotides from PCR products was carried out through ExoSAP. Samples were Sanger sequenced in an ABI 3730xl device (Applied Biosystems, Foster City, CA, USA), after labelling (BigDye Terminator v3.1; Thermo Fisher Scientific, Houston, USA) and purification (Agencourt ${ }^{\oplus}$ CleanSEQ $^{\circ}$; Agencourt Bioscience Corporation, Beverly, MA).

\section{Real time expression}

Quantitative PCR was performed as follows: $10 \mathrm{ng}$ of cDNA, $5 \mu \mathrm{M}$ of each primer and SensiFAST HRM Kit (Bioline Reagents Ltd., London, UK) were mixed and amplified using the RotorGene Q (Qiagen, Dusseldorf, Germany). Three individual replicates of cDNA obtained using Superscript III first strand synthesis kit, (Invitrogen, Gaithersburg, MD, USA) were quantified, and data analysis was performed using the LinReg software [42]. GADPH and $18 \mathrm{~S}$ were previously selected by GeNorm software [43], and were used as endogenous controls to calculate relative expression. Primer sequences and Tm are indicated in Additional file 4: Table S1.
The analysis of $\mathrm{X}$ and $\mathrm{Y}$ alleles in males was carried out as follows: primers were designed from a common region in each gene under analysis. The $\mathrm{X}$ and $\mathrm{Y}$ amplicons, which had SNPs between alleles, were cloned in pCR2.1 vector (TA Cloning, Invitrogen, Carlsbad, CA, USA) and X:Y ratios of 0:100; 25:75; 50:50; 75:25; 100:0 were used for the real time analysis. The differential expression of $\mathrm{X}$ and $\mathrm{Y}$ alleles was measured by High Resolution Melting analysis. Using the standard melt curve data, linear regression was used to calculate the $\mathrm{X}: \mathrm{Y}$ expression ratio in S. latifolia male tissues.

\section{Methylated DNA Immunoprecipitation DNA isolation}

A fresh weight of $300 \mathrm{mg}$ of S. latifolia vegetative leaves was used for DNA extraction by nuclei purification, as follows: a volume of $10 \mathrm{~mL}$ of Buffer A (0.44 M sucrose, $10 \mathrm{mM}$ Tris-HCl; $\mathrm{pH}$ 8.0, $5 \mathrm{mM} \beta-\mathrm{ME}$ and $0.15 \mathrm{mM}$ PMFS) was added to the frozen tissue powder and the samples were incubated in ice for $30 \mathrm{~min}$ with occasional shaking. Samples were filtered with a mousseline and centrifuged at $3000 \mathrm{~g}$ for $15 \mathrm{~min}$ at $4{ }^{\circ} \mathrm{C}$. Several extractions with Buffer B $(0.25 \mathrm{M}$ sucrose, $10 \mathrm{mM}$ Tris- $\mathrm{HCl} ; \mathrm{pH}$ 8.0, $10 \mathrm{mM} \mathrm{MgCl2,} \mathrm{1 \%} \mathrm{Triton} \mathrm{X-100,}$ $5 \mathrm{mM} \beta-\mathrm{ME}$ and $0.15 \mathrm{mM}$ PMSF) were used to remove organelles until the pellet was mostly white. It was resuspended in $8 \mathrm{~mL}$ of buffer $\mathrm{C}(0.25 \mathrm{M}$ sucrose, $10 \mathrm{mM}$ Tris- $\mathrm{HCl} ; \mathrm{pH} 8.0,10 \mathrm{mM} \mathrm{MgCl} 2,5 \mathrm{mM} \beta-\mathrm{ME}$ and $0.15 \mathrm{mM}$ PMSF) and centrifuged at $3000 \mathrm{~g}$ for $10 \mathrm{~min}$ at $4{ }^{\circ} \mathrm{C}$. Nuclei were re suspended in $1 \mathrm{~mL}$ of nuclei lysis buffer (50 mM Tris-HCl; pH 8, 10 mM EDTA, 1\% SDS and $15 \mu \mathrm{M}$ PMSF). Samples were phenol/chloroform purified and DNA was ethanol precipitated and quantified.

\section{DNA sonication}

An amount of $20 \mu \mathrm{g}$ of genomic DNA was diluted in $300 \mu \mathrm{L}$ of IP buffer (100 mM Na-phosphate; pH 7.0, 1.4 $\mathrm{M} \mathrm{NaCl}$ and $0.5 \%$ Triton $\mathrm{X}-100$ ) in a $1.5 \mathrm{~mL}$ tube. $\mathrm{A}$ total of 7 pulses of $90 \%$ intensity for $15 \mathrm{~s}$ for each sample at $4{ }^{\circ} \mathrm{C}$ were delivered with an ultrasonic processor UP50H (Hielscher Ultrasonics $\mathrm{GmbH}$, Teltow, Germany). Verification of the size of the fragment of sonicated DNA on a $2 \%$ agarose gel was carried out with an average size of $400 \mathrm{bp}$ and a range of from 200 to $800 \mathrm{bp}$. A total of $14 \mu \mathrm{g}$ of DNA was placed in two $1.5 \mathrm{~mL}$ tubes $(7 \mu \mathrm{g}$ of DNA per tube).

\section{Immunoprecipitation of methylated DNA}

Prior to the immunoprecipitation protocol, internal methylated and unmethylated standards were added to each sample for evaluation of immunoprecipitation performance (Diagenode, Seraing, Belgium). Samples were heat-denatured and immediately placed in ice for $10 \mathrm{~min}$. An aliquot of each sample was stored at $-20{ }^{\circ} \mathrm{C}$ 
as an input control. An amount of $10 \mu \mathrm{g}$ of antibody (monoclonal mouse anti-5-methylcytidine. Diagenode, Seraing, Belgium) was added to each sample. The mixture was incubated on a rotating platform at $4{ }^{\circ} \mathrm{C}$. Then to the DNA-antibody mixture, a volume of $50 \mu \mathrm{l}$ of magnetic Dynabeads ${ }^{\circ}$ Protein G (Invitrogen Life Technologies Corporation, Gaithersburg, MD, USA) was added. The samples were later incubated for $2 \mathrm{~h}$ on a rotating platform at $4{ }^{\circ} \mathrm{C}$. A magnetic rack (Invitrogen Life Technologies Corporation, Gaithersburg, MD, USA) was used to remove the supernatant and for the washing steps. In total we performed three washes and later on we resuspended the magnetic beads in $250 \mu \mathrm{l}$ of digestion buffer (50 mM Tris; $\mathrm{pH}$ 8.0, $10 \mathrm{mM}$ EDTA and $0.5 \%$ SDS) with $100 \mu \mathrm{g}$ of Proteinase K (Sigma Chemical Co., St. Louis, MO, USA). The digestion with Proteinase $\mathrm{K}$ was realized in a hybridization oven with rotation at $50{ }^{\circ} \mathrm{C}$.

\section{Purification of methylated DNA}

Samples were phenol extracted (phenol:chloroform:isoamyl alcohol $(v / \mathrm{v} 25: 24: 1))$ in $2 \mathrm{ml}$ heavy 5 prime phaselock tubes (Eppendorf-5 Prime, Inc., Boulder, CO, USA). DNA was ethanol precipitated overnight at $-80^{\circ} \mathrm{C}$ using $1.5 \mu$ glycogen $(20 \mathrm{mg} / \mathrm{mL})$ as an adjuvant. After centrifugation $\left(20,000 \mathrm{~g}\right.$ for $10 \mathrm{~min}$ at $\left.4{ }^{\circ} \mathrm{C}\right)$, the pellet was resuspended in TE buffer and quantified.

\section{Quantitative PCR}

Quantitative PCR was performed as follows: $10 \mathrm{ng}$ of immunoprecipitated DNA, $5 \mu \mathrm{M}$ of each primer and SensiFAST HRM Kit (Bioline Reagents Ltd., London, UK) were mixed according to manufacturer's instructions and amplified using the Rotor-Gene Q (Qiagen, Dusseldorf, Germany). Three regions from each gene were selected for amplification analysis, promoter region (500 bp upstream from transcription starting site), first exon and first intron. The exception was gene SlDD 44 which has a first exon of $80 \mathrm{bp}$. Given that recommended amplicon size should be over $100 \mathrm{bp}$, in this gene we used for amplification the region including the first exon, first intron and second exon. Four replicates for each transcript from a pool of individuals were analysed using the LinReg software [42]. Primer sequences and Tm are indicated in Additional file 4: Table S1.

\section{Statistical analysis}

Univariate analysis of variance (ANOVA) was carried out on all EST data using the glm procedure in $\mathrm{R}$ Studio (V1.0.143) to identify factor interactions. Multiple comparisons were then made with the post hoc Tukey's HSD test. Single comparisons were made using Student $t$-tests.

\section{Single cytosine resolution methylation}

The gene regions with significant differences in methylated DNA immunoprecipitation were selected for further analysis by bisulfite sequencing. DNA was converted using EZ DNA Methylation ${ }^{\text {Tx }}$ Kit (Zymo Research, California, USA). For amplification of the target sequence by PCR, modified primers using Bisprimer [44] and Methyl Primer Express v1.0 (Applied Biosystems, Foster City, CA, USA) were designed. According to $\mathrm{V}$ Kovacova and $\mathrm{B}$ Janousek [44], a nonselective variant primer $(\mathrm{Nv})$ which is able to bind methylated and no methylated modified DNA templates with the same efficiency, was designed. The amplified products were cloned in PCR2.1 vector (TA Cloning, Invitrogen, Carlsbad, CA, USA) and Sanger sequenced (Macrogen Ltd., Seoul, South Korea). The sequencing data of 30 clones from each amplification was analysed using Kismeth [45].

\section{Additional files}

\begin{abstract}
Additional file 1: Expression and methylation enrichment data. This is an excel file with the expression and methylation graphs belonging to the different genes under analysis in this work. There is also included an expression correlation plot between Silene latifolia and Silene vulgaris. (XLSX $156 \mathrm{~kb}$ )
\end{abstract}

Additional file 2: Gene sequence similarity. This is an excel file including the percentage of similarity when comparing the same region (e.g. promoter) of a gene in Silene vulgaris and in Silene latifolia $X$ and $Y$ alleles. (XLSX $16 \mathrm{~kb}$ )

Additional file 3: Bisulfite sequencing analysis. This is an excel file with the data of sodium bisulfite sequencing analysis from those regions in the different genes with a significant enrichment in the MeDIP experiment. These data were obtained to support the positive results in the MeDIP to confirm the methylation enrichment. A general methylation context plot is also included. (XLSX $16980 \mathrm{~kb}$ )

Additional file 4: Table S1. Primer list. List of primers used in this work. (XLSX 19 kb)

\section{Abbreviations}

MeDIP: Immunoprecipitation of methylated DNA; PAR: Pseudoautosomal region; RdDM pathway: RNA directed DNA methylation pathway; SPF: Stamen promoting function

\section{Acknowledgements}

We would like to thank Alex Oulton and Francisco Peinador Pascua for English corrections.

\section{Funding}

This work was supported by The Czech Science Foundation (P501/12/G090).

\section{Availability of data and materials}

All data generated or analysed during this study are included in this published article [and its Additional files].

\section{Authors' contributions}

$J L R L, R H$ and BV designed the study, interpreted the data and wrote the manuscript. JLRL performed experimental work. All authors read and approved the final manuscript.

\section{Ethics approval and consent to participate}

The seeds of S. latifolia belong to a collection of backcrossing seeds available in the department of "Plant Developmental Genetics" from the Institute of Biophysics V.v.i; Academy of Sciences of the Czech Republic. The seeds were 
grown in pots under greenhouse conditions and no field permissions were necessary to collect the plant samples for this study. The authors declared that experimental research works on the plants described in this paper comply with institutional, national and international guidelines.

\section{Consent for publication}

Not applicable.

\section{Competing interests}

The authors declare that they have no competing interests.

\section{Publisher's Note}

Springer Nature remains neutral with regard to jurisdictional claims in published maps and institutional affiliations.

Received: 26 March 2018 Accepted: 10 July 2018

Published online: 16 July 2018

\section{References}

1. Hobza R, Vyskot B. Sex chromosomes in plants. In: Teixeira da Silva J, editor. Floriculture, ornamental and plant biotechnology (Advances and Topical Issues), vol. I. Middlesex, UK: Global Science Books; 2006. p. 646

2. Hobza R, Kejnovsky E, Vyskot B, Widmer A. The role of chromosomal rearrangements in the evolution of Silene latifolia sex chromosomes. Mol Gen Genomics. 2007;278(6):633-8

3. Bergero R, Forrest A, Kamau E, Charlesworth D. Evolutionary strata on the $\mathrm{X}$ chromosomes of the dioecious plant Silene latifolia: evidence from new sex-linked genes. Genetics. 2007;175(4):1945-54.

4. Marais GA, Nicolas M, Bergero R, Chambrier P, Kejnovsky E, Moneger F, Hobza R, Widmer A, Charlesworth D. Evidence for degeneration of the $Y$ chromosome in the dioecious plant Silene latifolia. Curr Biol. 2008;18(7):545-9.

5. Kazama Y, Ishii K, Aonuma W, Ikeda T, Kawamoto H, Koizumi A, Filatov DA, Chibalina M, Bergero R, Charlesworth D et al: A new physical mapping approach refines the sex-determining gene positions on the Silene latifolia Y-chromosome. Sci Rep 2016, 6:18917.

6. Zluvova J, Janousek B, Negrutiu I, Vyskot B. Comparison of the $X$ and $Y$ chromosome organization in Silene latifolia. Genetics. 2005:170(3):1431-4.

7. Charlesworth D. Plant sex chromosome evolution. J Exp Bot. 2013;64(2):405-20.

8. Cermak T, Kubat Z, Hobza R, Koblizkova A, Widmer A, Macas J, Vyskot B, Kejnovsky E. Survey of repetitive sequences in Silene latifolia with respect to their distribution on sex chromosomes. Chromosom Res. 2008;16(7):961-76.

9. Kubat Z, Zluvova J, Vogel I, Kovacova V, Cermak T, Cegan R, Hobza R, Vyskot B, Kejnovsky E. Possible mechanisms responsible for absence of a retrotransposon family on a plant Y chromosome. New Phytol. 2014;202(2):662-78.

10. Li SF, Zhang GJ, Yuan JH, Deng CL, Gao WJ. Repetitive sequences and epigenetic modification: inseparable partners play important roles in the evolution of plant sex chromosomes. Planta. 2016;243(5):1083-95.

11. Sigman MJ, Slotkin RK. The first rule of plant transposable element silencing: location, location, location. Plant Cell. 2016;28(2):304-13.

12. Livernois AM, Waters SA, Deakin JE, Graves JAM, Waters PD. Independent evolution of transcriptional inactivation on sex chromosomes in birds and mammals. PLoS Genet. 2013:9(7):e1003635.

13. Waddington $\mathrm{CH}$. Towards a theoretical biology. Nature. 1968;218:525-7.

14. Takuno S, Ran J-H, Gaut BS. Evolutionary patterns of genic DNA methylation vary across land plants. Nature Plants. 2016;2(2):15222.

15. Niederhuth C, Schmitz R. Putting DNA methylation in context: from genomes to gene expression in plants. Biochim Biophys Acta. 2017;1860(1):149.

16. Bewick AJ, Niederhuth CE, Ji L, Rohr NA, Griffin PT, Leebens-Mack J, Schmitz RJ. The evolution of CHROMOMETHYLASES and gene body DNA methylation in plants. Genome Biol. 2017;18(1):65.

17. Pikaard C, Haag J, Pontes O, Blevins T, Cocklin R. A transcription fork model for pol IV and pol v-dependent RNA-directed DNA methylation. In: Cold spring Harb Symp quant biol: 2012: Cold Spring Harbor Laboratory Press NY USA; 2012. p. 205-12.

18. Zhang W, Wang $X$, Yu Q, Ming R, Jiang J. DNA methylation and heterochromatinization in the male-specific region of the primitive $Y$ chromosome of papaya. Genome Res. 2008;18(12):1938-43.

19. Gorelick R. Evolution of dioecy and sex chromosomes via methylation driving Muller's ratchet. Biol J Linn Soc. 2003;80(2):353-68.

20. Janoušek B, Široký J, Vyskot B. Epigenetic control of sexual phenotype in a dioecious plant, Melandrium album. Mol Gen Genet. 1996;250(4):483-90.
21. Hobza R, Cegan R, Jesionek W, Kejnovsky E, Vyskot B, Kubat Z. Impact of repetitive elements on the $Y$ chromosome formation in plants. Genes. 2017;8(11):302.

22. Li SF, Su T, Cheng GQ, Wang BX, Li X, Deng CL, Gao WJ. Chromosome evolution in connection with repetitive sequences and epigenetics in plants. Genes. 2017;8(10):290.

23. Farbos I, Oliveira M, Negrutiu I, Mouras A. Sex organ determination and differentiation in the dioecious plant Melandrium album (Silene latifolia): a cytological and histological analysis. Sexual Plant Reprod. 1997;10(3):155-67.

24. Blavet N, Blavet H, Muyle A, Käfer J, Cegan R, Deschamps C, Zemp N, Mousset S, Aubourg S, Bergero R. Identifying new sex-linked genes through BAC sequencing in the dioecious plant Silene latifolia. BMC Genomics. 2015;16(1):546.

25. Čegan R, Marais GA, Kubekova H, Blavet N, Widmer A, Vyskot B, Dolezel J, Safar J, Hobza R. Structure and evolution of Apetala3, a sex-linked gene in Silene latifolia. BMC Plant Biol. 2010;10:180.

26. Papadopulos AS, Chester M, Ridout K, Filatov DA. Rapid Y degeneration and dosage compensation in plant sex chromosomes. Proc Natl Acad Sci U S A. 2015;

27. Filatov DA. Evolutionary history of Silene latifolia sex chromosomes revealed by genetic mapping of four genes. Genetics. 2005;170(2):975-9.

28. Hobza R, Kubat Z, Čegan R, Jesionek W, Vyskot B, Kejnovsky E. Impact of repetitive DNA on sex chromosome evolution in plants. Chromosom Res. 2015;23(3):561-70.

29. Bräutigam K, Soolanayakanahally R, Champigny M, Mansfield S, Douglas C, Campbell MM, Cronk Q. Sexual epigenetics: gender-specific methylation of a gene in the sex determining region of Populus balsamifera. Sci Rep. 2017;7:45388.

30. Susan JC, Harrison J, Paul CL, Frommer M. High sensitivity mapping of methylated cytosines. Nucleic Acids Res. 1994;22(15):2990-7.

31. Gehring M. Prodigious plant methylomes. Genome Biol. 2016;17(1):197.

32. Feng S, Cokus SJ, Zhang X, Chen P-Y, Bostick M, Goll MG, Hetzel J, Jain J, Strauss $\mathrm{SH}$, Halpern ME. Conservation and divergence of methylation patterning in plants and animals. Proc Natl Acad Sci U S A. 2010;107(19):8689-94.

33. Zemach A, McDaniel IE, Silva P, Zilberman D. Genome-wide evolutionary analysis of eukaryotic DNA methylation. Science. 2010;328(5980):916-9.

34. Zakrzewski F, Schmidt M, Van Lijsebettens M, Schmidt T. DNA methylation of retrotransposons, DNA transposons and genes in sugar beet (Beta vulgaris L.). Plant J. 2017;90(6):1156-75.

35. Li Q, Gent Jl, Zynda G, Song J, Makarevitch I, Hirsch CD, Hirsch CN, Dawe RK, Madzima TF, McGinnis KM. RNA-directed DNA methylation enforces boundaries between heterochromatin and euchromatin in the maize genome. Proc Natl Acad Sci. 2015;112(47):14728-33.

36. Gent Jl, Ellis NA, Guo L, Harkess AE, Yao Y, Zhang X, Dawe RK. CHH islands: de novo DNA methylation in near-gene chromatin regulation in maize. Genome Res. 2013;23(4):628-37.

37. Huang J, Lynn J, Schulte L, Vendramin S, McGinnis K. Chapter two-epigenetic control of gene expression in maize. Int Rev Cell Mol Biol. 2017;328:25-48.

38. Hsu FM, Yen MR, Wang CT, Lin CY, Wang CR, Chen PY. Optimized reduced representation bisulfite sequencing reveals tissue-specific $\mathrm{mCHH}$ islands in maize. Epigenetics Chromatin. 2017;10(1):42.

39. Cokus SJ, Feng S, Zhang X, Chen Z, Merriman B, Haudenschild CD, Pradhan S, Nelson SF, Pellegrini M, Jacobsen SE. Shotgun bisulphite sequencing of the Arabidopsis genome reveals DNA methylation patterning. Nature. 2008; 452(7184):215-9.

40. Blavet N, Blavet H, Čegan R, Zemp N, Zdanska J, Janousek B, Hobza R, Widmer A. Comparative analysis of a plant pseudoautosomal region (PAR) in Silene latifolia with the corresponding S. vulgaris autosome. BMC Genomics. 2012;13:226.

41. Chibalina MV, Filatov DA. Plant Y chromosome degeneration is retarded by haploid purifying selection. Curr Biol. 2011;21(17):1475-9.

42. Ruijter J, Ramakers C, Hoogaars W, Karlen Y, Bakker O, Van den Hoff M, Moorman A. Amplification efficiency: linking baseline and bias in the analysis of quantitative PCR data. Nucleic Acids Res. 2009;37(6):e45.

43. Vandesompele J, De Preter K, Pattyn F, Poppe B, Van Roy N, De Paepe A, Speleman F. Accurate normalization of real-time quantitative RT-PCR data by geometric averaging of multiple internal control genes. Genome Biol. 2002;3(7):research0034. 0031.

44. Kovacova $V$, Janousek B. Bisprimer-a program for the design of primers for bisulfite-based genomic sequencing of both plant and mammalian DNA samples. J Hered. 2012;103(2):308-12.

45. Gruntman E, Qi Y, Slotkin RK, Roeder T, Martienssen RA, Sachidanandam R. Kismeth: analyzer of plant methylation states through bisulfite sequencing. BMC bioinformatics. 2008;9(1):371. 